\title{
PENGEMBANGAN PERANGKAT LUNAK GENERATE FILE UNTUK MIGRASI DATA EPSBED KE FORMAT TABLE FEEDER PDDIKTI
}

\author{
Teknik Informatika, Universitas Palangka Raya
}

\author{
Kampus Tunjung Nyaho Jalan Yos Sudarso, Palangka Raya, \\ Kalimantan Tengah
}

Viktor Handrianus Pranatawijaya ${ }^{1}$, Putu Bagus Adidyana Anugrah Putra ${ }^{2}$, Vincentius Abdi Gunawan ${ }^{3}$

Email:viktor_hp@yahoo.com, putu.upr@gmail.com, abdi_gnwn@yahoo.com

\begin{abstract}
Based on SK-03, DIKTI requires all universities provide a report on each semester that corresponding to the report format named EPSBED. EPSBED report is one indicator of a study program at the college as it is called active and abiding by the principle. The reporting of data is conducted every semester and should be reported such as the data of students, the data of subjects, the data of lectures, the value of relocation, the lectures activities of students, and the status of students.

The research MADE data migration software used library research and observation. Furthermore, processing the EPSBED data to excel in accordance with the template of PDDIKTI Feeder preceded by mapping EPSBED table with PDDKTI Feeder table.Determine the functionality of the software, made the design and implemented in the programming language of PHP. The software testing was conducted using EPSBED data of Informatics Engineering Department Palangka Raya University

The software developed produce excel file containing the data of students (profile and status), the data of subjects and the assessment, the data of lectures (class lectures, students KRS, lecturer, subjects, and students grade), and the lectures activities of students. Data Migration Software to PDDIKTI Feeder to assist and facilitate the reporting of PDPT UPR. In other words, Data Migration Software to PDDIKTI Feeder can be a model and reference in the subsequent development, in which an existing excel file with the help of Web Service PDDIKTI Feeder can be inputted the data into the feeder DIKTI so that it can be displayed on Forlap DIKTI.
\end{abstract}

Keywords: PDDIKTI Feeder, Data Migration, EPSBED, and UPR 


\section{PENDAHULUAN}

Untuk meningkatkan penjaminan mutu, relevansi, keterjangkauan, pemetaan yang berkeadilan dan akses pendidikan tinggi yang berkelanjutan sesuai dengan yang diamanatkan oleh Keputusan Menteri Pendidikan Nasional 184/U/2001 pasal 5, maka dibuatlah Feeder PDDIKTI yang diharapkan dapat menjadi salah satu wujud harapan tersebut. Feeder PDDIKTI akan menjadi satu-satunya aplikasi pelaporan data nasional, sehingga semua laporan akan masuk melalui satu pintu yaitu Feeder PDDIKTI. Aplikasi Feeder PDDIKTI ini juga sebagai jembatan antara Sistem Informasi Akademik

yang dimiliki oleh perguruan tinggi dengan Pangkalan Data Pendidikan Tinggi (PDDIKTI) sebagai database DIKTI.

PDDIKTI merupakan kumpulan data penyelenggaraan Pendidikan Tinggi seluruh Perguruan Tinggiyangterintegrasi secara nasional terdokumentasi pada laman forlap.dikti.go.id.PDDIKTI menjadi salah satuinstrument pelaksanaan penjaminan mutu. Dalam pasal 56 ayat2 UU No. 12 Tahun 2012 tentang Pendidikan Tinggimenyebutkan bahwa Pangkalan Data Pendidikan Tinggi sebagaimana dimaksud pada ayat (1) berfungsi sebagai sumber informasi bagi: 1. Lembaga akreditasi, untuk melakukan akreditasi Program Studi danPerguruan Tinggi; 2. Pemerintah, untuk melakukan pengaturan, perencanaan, pengawasan, pemantauan, dan evaluasiserta pembinaan dan koordinasi Program Studi danPerguruan Tinggi; dan3: Masyarakat, untuk mengetahui kinerja Program Studi dan Perguruan Tinggi.

Pelaporan data ini dilakukan setiap semester dan yang harus dilaporkan antara lain adalah data mahasiswa, data mata kuliah, data perkuliahan, nilai pindahan, aktifitas kuliah mahasiswa dan status mahasiswa. Yang menjadi permasalahan adalah Feeder PDDIKTI tidak menyediakan fitur import data ke Feeder yang artinya operator harus meng-inputkan satu persatu data ke aplikasi Feeder. Sementara data yang harus dilaporkan itu ribuan. Tentu saja hal ini menghabiskan banyak waktu karena data yang harus dilaporkan tidak sedikit. Maka dari itu perlu adanya pengembangan perangkat lunak generate file untuk migrasi data EPSBED ke format tabel Feeder PDDIKTI. 
Berdasarkan penjabaran di atas, beberapa permasalahan penelitian yang dapat dirumuskan adalah bagaimana mengubah file.dbf pada ESBED yang telah ditentukan menjadi file templateexcel yang telah dipetakan dengan tabel Feeder PDDIKTI yang berisi data Data Mahasiswa (biodata dan status), Data Mata Kuliah beserta bobot penilaiannya, Data Kelas Perkuliahan (kelas kuliah, KRS mahasiswa, dosen, mata kuliah, dan nilai mahasiswa) dan Aktifitas Kuliah Mahasiswa.

Dengan kata lain, dapat disimpulkan bahwa sangatlah perlu suatu penelitian untuk mengembangkan pengembangan perangkat lunak generate file untuk migrasi data EPSBED ke format tabel Feeder PDDIKTI. Hal tersebut sangat mungkin dicapai dikarenakan data EPSBED UPR dapat diubah menjadi file excel kemudian file excel itu akan diubah secara otomatis menjadi templateexcel yang nantinya akan di-import-kan dengan menerapkan Web Service Feeder PDDIKTI ke Feeder PDDIKTI.

\section{TUJUAN}

Tujuan dari penelitian ini adalah mengembangan perangkat lunak generate file untuk migrasi data EPSBED ke format tabel Feeder PDDIKTI dapat dilakukan dengan cara:

a. Memetakan tabel EPSBED dengan tabel Feeder PDDIKTI.

b. Mengolah data EPSBED ke file excel sesuai dengan template Feeder PDDIKTI.

\section{TINJAUAN PUSTAKA}

Sistem informasi adalah kombinasi dari manusia, fasilitas atau alat teknologi, media, prosedur dan pengendalian yang ditujukan untuk mengatur jaringan komunikasi yang penting, proses transaksi tertentu dan rutin, membantu manajemen dan pemakai intern dan ekstern dan menyediakan dasar untuk pengambilan keputusan yang tepat. Di zaman modern seperti saat ini, sistem informasi telah menjadi bagian penting di semua bidang, termasuk memberikan kesempatan bagi organisasi untuk mengintegrasikan seluruh elemen hingga strategi bisnis organisasi tersebut dapat tercapai (Salwe, A.M.I, Sharif. L, Ahmed, M, 2011). Salah satu penerapan dari sistem informasi adalah EPSBED.

Salah satu indikator suatu program studi pada perguruan tinggi yang masih aktif dan taat azaz adalah 
dengan melihat laporan EPSBED. Sejak mulai diluncurkanya pada tahun 2001 (pada saat itu disebut dengan istilah SK 034). Dalam perkembangannya EPSBED yang masih menggunakan visual basic pada awal peluncuran kemudian menggunakan versi DOS (EPSBED Biru yang masih di pakai sampai saat ini), kemudian berubah menjadi WinEPSBED, lalu menjadi PDPT dan saat ini kembali lagi menggunakan versi DOS (EPSBED Biru) dan akhirnya menggunakan Feeder PDDIKTI.

Pada pelaksanaannya sangat sulit bagi Kopertis untuk mencapai $100 \%$ dalam pengumpulan laporan EPSBED dari perguruan tinggi, hal ini disebabkan oleh beberapa hal misalnyatidak semua program studi yang dimiliki perguruan tinggi aktif (program studi tersebut tidak memiliki mahasiswa), dan kurangnya perhatian perguruan tinggi pada saat itu tentang penting laporan EPSBED.

Pada akhir tahun 2009 dibuat aturan baru bahwa laporan EPSBED menjadi salah satu syarat utama untuk pengusulan perpanjangan ijin program studi. Hal ini yang membantu untuk memberikan pemahaman tentang pentingnya laporan EPSBED. Dengan adanya aturan tersebut Kopertis tidak perlu lagi bersusah payah mengingatkan perguruan tinggi untuk memberikan laporan. Apabila perguruan tinggi tidak memberikan laporan EPSBED maka dengan sendirinya perpanjangan ijin program studi tidak bisa diproses.

Pada tahun 2013 perpanjangan ijin program studi dilebur ke dalam proses akreditasi, dengan kata lain bahwa setiap program studi yang status akreditasi masih berlaku berarti status perpanjangan ijin masih berlaku, demikian pula sebaliknya.

Dengan berlakunya peraturan tersebut di atas menimbulkan kekhawatiran baru tentang bagaimana nasibnya laporan EPSBED, karena dengan hilangnya proses perpanjangan ijin program studi maka berkurang salah satu kekuatan dari EPSBED itu sendiri. Berdasarkan kekhawatiran tersebut Dikti mengeluarkan aturan baru yaitu dengan mengkaitkan EPSBED kepada Serdos (sertifikasi dosen), yaitu bagi perguruan tinggi yang menyerahkan laporan EPSBED nya di bawah $90 \%$ maka proses sertifikasi dosennya untuk sementara di tunda.

Hal penting dari semua itu sebenarnya apa manfaat EPSBED itu sendiri bagi perguruan tinggi dan 
Kopertis. Ada beberapa keuntungan dan manfaat yang di peroleh dari data ESPBED tersebut yaitu :

a. Bagi stakeholder dapat dengan mudah memperoleh informasi calon tenaga kerja

b. Bagi Kopertis laporan EPSBED sangat bermanfaat dalam proses pemberian beasiswa PPA, BBM dan Bidik Misi.

c. Pada tahun ini banyak permohonan legalisir ijazah yang ijazahnya dikeluarkan pada tahun 2001 kebawah yang ternyata dipergunakan sebagai syarat menjadi calon legislatif (caleg). Ternyata inilah salah satu pentingnya laporan EPSBED sehingga Kopertis tidak tertipu dalam melegalisir ijasah dan juga bagi perguruan tinggi semua lulusan dapat terjamin.

d. Bagi perguruan tinggi yang akan mewisuda lulusanya data EPSBED menjadi acuanya, bila semua calon wisudawan terdaftar dalam data EPSBED maka Kopertis berkenan untuk mengahadiri wisudanya.

Dengan begitu besarnya keuntungan dan manfaat yang diperoleh dari data EPSBED tersebut bertambah besar pula harapan kita bahwa setiap perguruan tinggi dapat melaporkan proses kegiatan belajar mengajarnya melalu EPSBED dan dapat memberikan laporan sesuai dengan keadaan yang sebenarnya.

Pada tahun 2015 EPSBED dikembangkan dan digantikan menjadi Feeder PDDIKTI. Dalam perkembangannya migrasi data dari EPSBED ke Feeder PDDIKTI dapat dilakukan dengan membuat mapping tabel EPSBED dengan Feeder PDDIKTI. Sehingga kecocokan data antar tabel diantara dua sistem dapat dibandingkan (DIKTI 2015). Sebagai contoh: tabel MSMHS EPSBED dibandingkan dengan tabel mahasiswa dan mahasiswa_pt Feeder PDDIKTI yang berguna untuk data mahasiswa. Tabel TRLSM EPSBED dibandingkan dengan tabel mahasiswa_pt Feeder PDDIKTI yang berguna untuk data lulusan mahasiswa. Tabel TRNLM EPSBED dibandingkan dengan tabel kelas_kuliah, nilai Feeder PDDIKTI yang berguna untuk data akademik mahasiswa. Tabel TRAKD EPSBED dibandingkan dengan tabel ajar_dosen Feeder PDDIKTI yang berguna untuk data mengajar dosen. Tabel TRAKM EPSBED dibandingkan dengan tabel kuliah_mahasiswa Feeder PDDIKTI 
yang berguna untuk data aktifitas perkuliahan mahasiswa.

\section{METODOLOGI PENELITIAN}

Bahan penelitian sebagai fokus dan variabel utama dalam penelitian ini adalah perangkat lunak migrasi data Perangkat lunak migrasi data yang diteliti memiliki keterkaitan dengan data akademik dan website.

Objek yang dipilih adalah data EPSBED Program Studi Teknik Informatika Fakultas Teknik Universitas Palangka Raya. Sehingga perangkat lunak migrasi data yang dibuat dapat memigrasi data EPSBED program studi ke Feeder PDDIKTI.

Penelitian yang dilakukan adalah membuatan perangkat lunak migrasi data yang dilakukan dengan melakukan studi pustaka dan observasi kemudian mengolah data EPSBED ke file excel sesuai dengan templateFeeder PDDIKTI yang didahului dengan memetakan tabel EPSBED dengan tabel Feeder PDDIKTI. Menentukan fungsionalitas perangkat lunak dan membuat desainnya lalu diimplementasikan dalam bahasa pemrograman $P H P$. Untuk Pengujian perangkat lunak dilakukan dengan menggunakan data EPSBED jurusan
Teknik Informatika Universitas Palangka Raya.

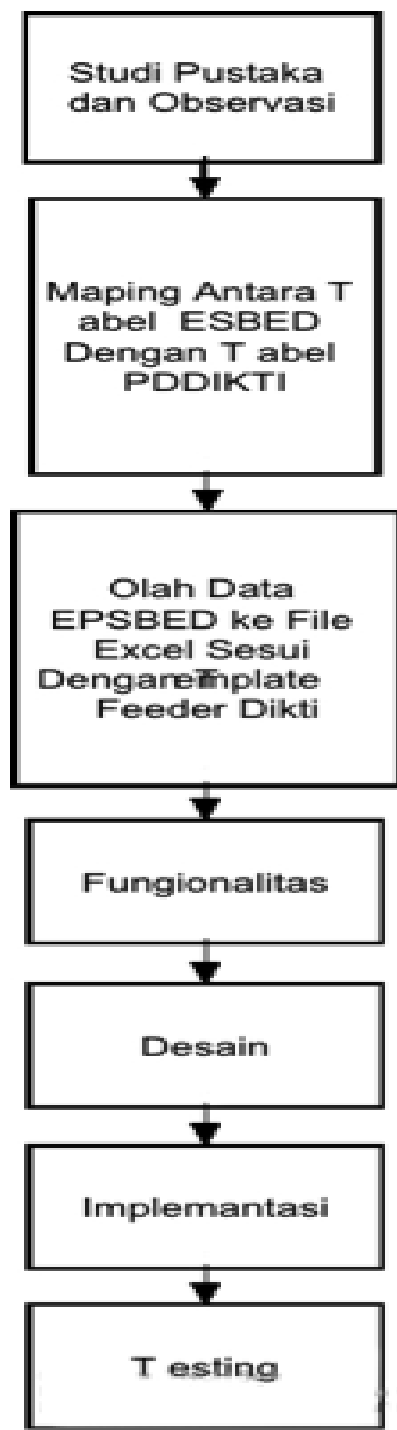

Gambar 1. Skema Alur Penelitian

\section{PEMBAHASAN}

Agar data dari tabel .dbf dapat diinputkan dan dimigrasikan ke dalam Feeder DIKTI maka diperlukan pemetaan data-data apa saja yang sama pada tabel Feeder DIKTI. Untuk lebih jelasnya dapat dilihat pada tabel 1 . 
Tabel 1. Maping Tabel

\begin{tabular}{|c|c|c|c|c|}
\hline No & Data & Isi Data & $\begin{array}{l}\text { Tabel } \\
\text { Feeder }\end{array}$ & $\begin{array}{l}\text { Tabel } \\
\text { ESBED }\end{array}$ \\
\hline 1 & $\begin{array}{l}\text { Data } \\
\text { Mah } \\
\text { asis } \\
\text { wa }\end{array}$ & $\begin{array}{l}\text { Biodata } \\
\text { mahasis } \\
\text { wa } \\
\text { Status } \\
\text { Mahasi } \\
\text { swa }\end{array}$ & $\begin{array}{l}\text { mahasiw } \\
\text { a } \\
\text { mahasiw } \\
\text { a_pt }\end{array}$ & $\begin{array}{l}\text { MSMH } \\
\text { S } \\
\text { TRLS } \\
\text { M }\end{array}$ \\
\hline 2 & $\begin{array}{l}\text { Data } \\
\text { Mat } \\
\text { a } \\
\text { Kuli } \\
\text { ah }\end{array}$ & $\begin{array}{l}\text { Bobot } \\
\text { Penilaia } \\
\mathrm{n}\end{array}$ & $\begin{array}{l}\text { bobot_nil } \\
\text { ai }\end{array}$ & $\begin{array}{l}\text { TBKM } \\
\text { K } \\
\text { TBBN } \\
\text { L }\end{array}$ \\
\hline 3 & $\begin{array}{l}\text { Data } \\
\text { Kela } \\
\text { s } \\
\text { Perk } \\
\text { uliah } \\
\text { an }\end{array}$ & $\begin{array}{l}\text { Kelas } \\
\text { Kuliah, } \\
\text { Kartu } \\
\text { Rencan } \\
\text { a Studi } \\
\text { (KRS), } \\
\text { Dosen, } \\
\text { Mata } \\
\text { Kuliah, } \\
\text { Nilai } \\
\text { Mahasi } \\
\text { swa }\end{array}$ & $\begin{array}{l}\text { mata_kul } \\
\text { iah } \\
\text { ajar_dose } \\
\text { n }\end{array}$ & $\begin{array}{l}\text { TRNL } \\
\text { M } \\
\text { TRAK } \\
\text { D } \\
\text { TBKM } \\
\text { K }\end{array}$ \\
\hline 4 & $\begin{array}{l}\text { Akti } \\
\text { fitas } \\
\text { Kuli } \\
\text { ah } \\
\text { Mah } \\
\text { asis } \\
\text { wa }\end{array}$ & $\begin{array}{l}\text { SKS } \\
\text { Semest } \\
\text { er } \\
\text { SKS } \\
\text { Total } \\
\text { IP } \\
\text { Semest } \\
\text { er } \\
\text { IPK } \\
\text { Status } \\
\text { Mahasi } \\
\text { swa }\end{array}$ & $\begin{array}{l}\text { kuliah_m } \\
\text { ahasiswa }\end{array}$ & $\begin{array}{l}\text { TRAK } \\
\text { M }\end{array}$ \\
\hline
\end{tabular}

Berdasarkan tabel dari EPSBED dan tampilan dari Feeder DIKTI maka dapat dibentuk template file excel yang nantinya akan digunakan sebagai tempat data untuk import ke aplikasi Feeder DIKTI menggunakan Web Service. Template File yang dibuat adalah Data Mahasiswa (dengan sheet biodata dan status), Data Mata Kuliah, Data Bobot
Nilai, Data Kelas Perkuliahan (dengan sheet kelas kuliah, KRS mahasiswa, dosen, mata kuliah, dan nilai mahasiswa), dan Aktifitas Kuliah Mahasiswa. Setiap migrasi data memiliki kebutuhan khusus dan berbeda-beda di setiap migrasi data, karena karakteristik mereka tergantung pada sistem yang ada dan data yang dipindahkan (Vodomin. G, Andročec. D, 2015).

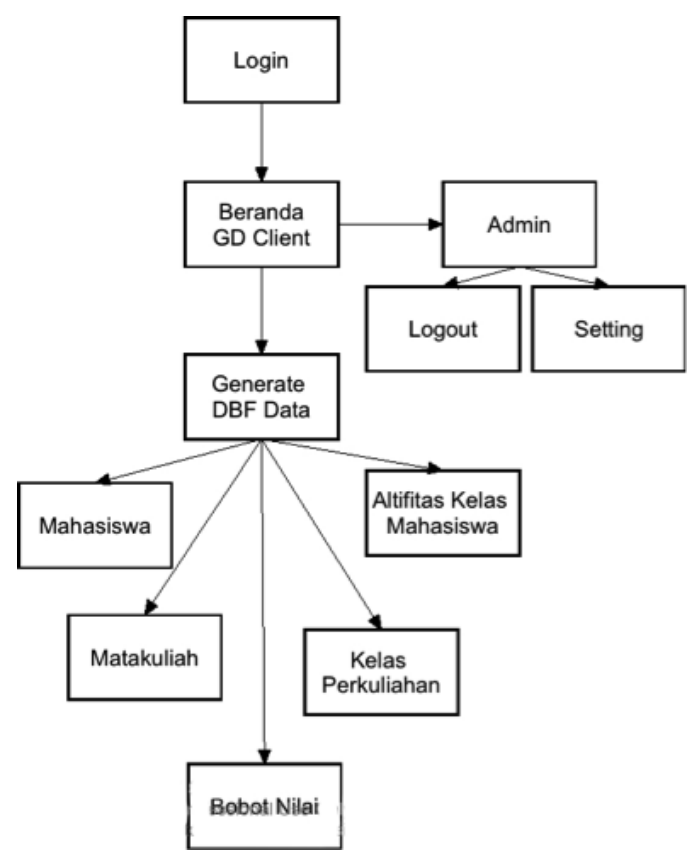

Gambar 2. Desain Navigasi 


\section{Login}

1. Memasukkan username dan password serta versi live atau sandbox menekan tombol login.

2. Login benar tampilkan halaman beranda, login tidak benar tampil pesan kesalahan.

\section{Beranda/GD Client}

1. Menampilkan data Prodi dengan memanggil fungsi GetRecordset dari tabel SMS.

2. Menampilkan menu Generate DBF Data.

\section{Generate DBF Data}

- Mahasiswa

1. Melakukan pembuatan file excel.

2. Melakukan query pada tabel MSMHS untuk biodata mahasiswa.

3. Melakukan assignment untuk field dari query tersebut ke variabelvariabel.

4. Melakukan perulangan untuk menuliskan variabel-variabel yang di atas ke sheet pertama di excel yang telah ditentukan.

5. Melakukan query pada tabel TRLSM untuk status lulus/DO mahasiswa.
6. Melakukan assignment untuk field dari query tersebut ke variabelvariabel.

7. Melakukan perulangan untuk menuliskan variabel-variabel yang di atas ke sheet kedua di excel yang telah ditentukan.

- Matakuliah

1. Melakukan pembuatan file excel.

2. Melakukan query pada tabel TBKMK untuk mata kuliah.

3. Melakukan assignment untuk field dari query tersebut ke variabelvariabel.

4. Melakukan perulangan untuk menuliskan variabel-variabel yang di atas ke sheet pertama di excel yang telah ditentukan.

- Bobot Nilai

1. Melakukan pembuatan file excel.

2. Melakukan query pada tabel TBBNL untuk bobot nilai.

3. Melakukan assignment untuk field dari query tersebut ke variabelvariabel.

4. Melakukan perulangan untuk menuliskan variabel-variabel yang di atas ke sheet pertama di excel yang telah ditentukan.

- Kelas Perkuliahan

1. Melakukan pembuatan file excel. 
2. Melakukan query pada tabel TRNLM, TBKMK, dan TRAKD untuk kelas perkuliahan.

3. Melakukan assignment untuk field dari query tersebut ke variabelvariabel.

4. Melakukan perulangan untuk menuliskan variabel-variabel yang di atas ke sheet pertama di excel yang telah ditentukan.

5. Melakukan query pada tabel TRNLM dan TRAKD untuk KRS.

6. Melakukan assignment untuk field dari query tersebut ke variabelvariabel.

7. Melakukan perulangan untuk menuliskan variabel-variabel yang di atas ke sheet kedua di excel yang telah ditentukan.

8. Melakukan pembuatan file excel.

9. Melakukan query pada tabel TRAKD dan TRNLM untuk dosen yang mengajar.

10. Melakukan assignment untuk field dari query tersebut ke variabelvariabel.

11. Melakukan perulangan untuk menuliskan variabel-variabel yang di atas ke sheet ketiga di excel yang telah ditentukan.

12. Melakukan query pada tabel TRNLM dan TRAKD untuk nilai.
13. Melakukan assignment untuk field dari query tersebut ke variabelvariabel.

14. Melakukan perulangan untuk menuliskan variabel-variabel yang di atas ke sheet keempat di excel yang telah ditentukan.

- Aktifitas Kuliah Mahasiswa

1. Melakukan query pada tabel TRAKM dan MSMHS untuk data aktifitas kuliah mahasiswa.

2. Melakukan assignment untuk field dari query tersebut ke variabelvariabel.

3. Melakukan perulangan untuk menuliskan variabel-variabel yang di atas ke sheet pertama di excel yang telah ditentukan.

Admin

- $\quad$ Setting

1. Menginputkan data Direktori DBF EPSBED, Semester Aktif DBF EPSBED, dan kode prodi DBF EPSBED.

2. Menekan tombol simpan yang akan melakukan penyimpanan data pada fileteks, jika data tidak terisi semua maka akan muncul pesan kesalahan 
- $\quad$ Logout

1. Menghancurkan session yang terbentuk.

2. Keluar dari system.

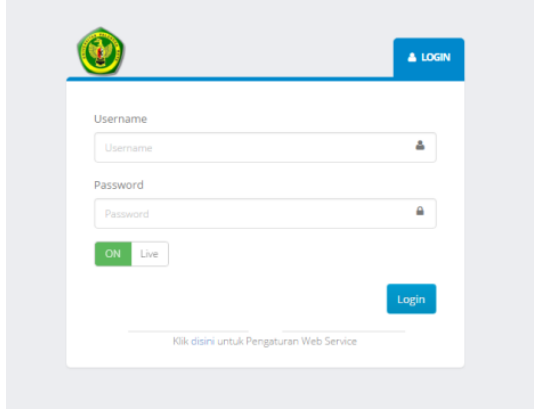

Gambar 3. Halaman Login

Gambar 4. Halaman GD Client

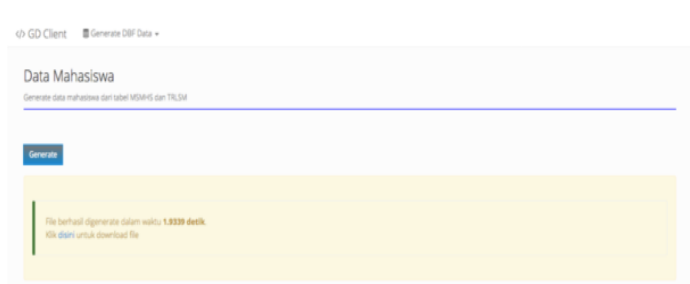

Gambar 5. Generate File Template Data

Mahasiswa

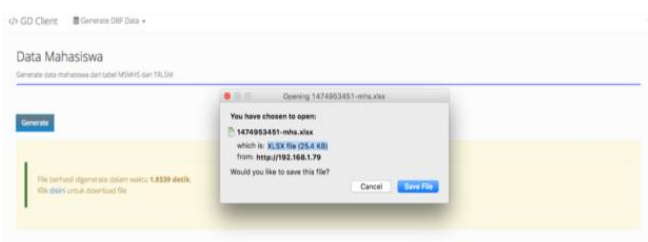

Gambar 6. Download File Template
Data Mahasiswa

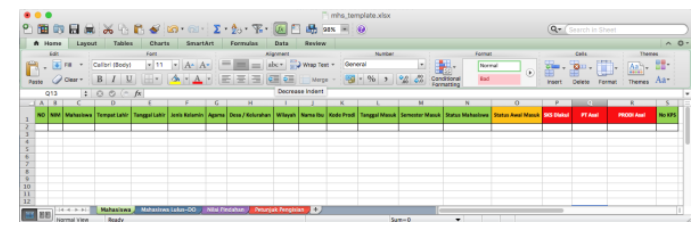

Gambar 7. File Template Data Mahasiswa

\section{KESIMPULAN}

Pembuatan perangkat lunak migrasi data dilakukan dengan melakukan studi pustaka dan observasi kemudian mengolah data EPSBED ke file excel sesuai dengan template Feeder PDDIKTI yang didahuli dengan memetakan tabel EPSBED dengan tabel Feeder PDDIKTI. Menentukan fungsionalitas perangkat lunak dan membuat desainnya lalu diimplementasikan dalam bahasa pemrograman PHP.

Perangkat lunak yang dikembangkan menghasilkan file excel yang berisi data Data Mahasiswa (biodata dan status), Data Mata Kuliah beserta bobot penilaiannya, Data Kelas Perkuliahan (kelas kuliah, KRS mahasiswa, dosen, mata kuliah, dan nilai mahasiswa) dan Aktifitas Kuliah Mahasiswa. Perangkat Lunak Migrasi Data ke Feeder PDDIKTI untuk membantu dan memudahkan pelaporan PDPT UPR. Dengan kata lain, Perangkat Lunak Migrasi Data ke 
Feeder PDDIKTI dan bisa menjadi model dan acuan dalam pengembangan selanjutnya dimana file excel yang sudah ada dengan menggunakan bantuan Web ServiceFeeder PDDIKTI, dapat diimputkan datanya ke Feeder PDDIKTI sehingga datanya dapat ditampilkan pada Forlap DIKTI.

\section{DAFTAR PUSTAKA}

PDDIKTI. 2016, User Guide Modul Web Service, Sistem Informasi Manajemen Akademik, DIKTI

Vodomin. G, Andročec. D, 2015. Problems during Database Migration to the Cloud, Central European Conference on Information and Intelligent Systems, September 23-25, 2015.

DIKTI. 2015, Dokumen Mapping Table EPSBED dan Web Service, Aplikasi Pangkalan Data Pendidikan Tinggi (PDDIKTI), DIKTI

Salwe. A.M.I, Sharif. L, Ahmed, M, 2011, Strategic Information Systems Planning as the Centre of Information Systems Strategies, International Journal of Research and Reviews in Computer Science (IJRRCS), Vol. 2, No. 1, March 2011

F Nash, John, diterjemahkan oleh La Midjan. 2003. "Sistem Informasi Akuntansi I Pendekatan Manual Pratika Penyusunan Metode dan Prosedur". Bandung : Lembaga Informatika Akuntansi. 